\title{
Assessment of helminth parasites of pigs in Ibadan, Nigeria
}

Adenaike, E. A.

Department of Veterinary Medicine,

Michael Okpara University of Agriculture, Umudike, Abia State

Corresponding author: adenaikelara@yahoo.com; +2348026580689

Abstract

Gastro-intestinal parasitism constitutes an important constraint to pig production in most parts of the world and in Nigeria. These gastrointestinal helminthoses in pigs occasionally cause obvious disease and death, but more commonly, they lead to loss of appetite, reduced weight gain, poor feed utilization, potentiation of other pathogens and condemnation of parts of the carcasses at slaughter. An assessment of helminth parasites of pigs in Ibadan, Nigeria was investigated in this study. A total of 154 pigs of both sexes of Large White, Indigenous and Crosses breeds found were sampled and standard parasitological examinations were carried out on the faecal samples. Out of the 154 pigs examined, $36.36 \%$ were positive for helminth parasites of which $24.67 \%$ were males, $11.69 \%$ were females and the remaining $63.64 \%$ were negative for helminth parasites. The eggs of helminth parasites found in this study were those of Ascaris spp. (12.34\%), Metastrongylus spp. (9.74\%), Oesophagostomum spp. (6.49\%), Paragonimus spp. (1.3\%), Hyostrongylus spp. (1.3\%) and Trichuris spp. (5.19\%). Helminth parasites were most prevalent in large white breed of the pigs (27.27\%) the crosses (6.49\%) and least prevalent in indigenous breeds (2.60\%). Eggs of Ascaris spp. (12.34\%) and Metastrongylus spp. (9.74\%) are the commonest helminth parasite eggs of pigs found in the study while Trichuris spp. had the highest (29.07\%) mean eggs per gramme of faeces. In conclusion, regular assessment of helminth parasites in the faeces of pigs in recommended for strategic treatment against helminth parasites and pig farmers are encouraged to prevent the environment from becoming contaminated by infective helminth larvae by practicing good standards of hygiene.

Keywords: Assessment, Helminths, Pigs, Ibadan, Nigeria

\section{Introduction}

Gastro-intestinal helminthosis is a disease complex caused by multicellular endoparasitic trematodes, cestodes and nematodes within the gastro-intestinal tract of animals but of major importance are those diseases caused by parasitic nematodes (Talabi et al., 2003). Gastrointestinal parasitism constitutes an important constraint to pig production in most parts of the world and in Nigeria. Important intestinal parasites of pigs include Ascaris suum, Oesophagostomum dentatum, O. quadrispinulatum, Hyostrongylus rubidus, Ascarops strongylina, A. dentata, Physocephalus sexalatus, Strongyloides ransomi and Trichuris suis (Talabi et al., 2010). These gastrointestinal helminthoses in pigs occasionally cause obvious disease and death, but more commonly, they lead to loss of appetite, reduced weight gain, poor feed utilization, potentiation of other pathogens and condemnation of parts of the carcasses at slaughter. Developmental stages of some of these parasites penetrate the mucous membrane thereby compromising the defense mechanisms and often leading to secondary bacterial infections. The ensuing inflammatory reaction may interfere with the process of digestion or utilization of products of digestion. Other larvae may penetrate through the intestinal wall to cause peritonitis, hepatic lesions, pneumonia among others; leading to illhealth or condemnation of affected organs at slaughter. On the other-hand, adult worms not only compete for feed with the 


\section{Assessment of helminth parasites of pigs in Ibadan, Nigeria}

host, but some like A. suum may become entwined within the lumen to cause intestinal obstruction (Karanja et al., 2003). These parasites abound in Nigerian pigs throughout the year and are major constraints to the swine industry (Talabi et al., 2010). Southwestern Nigeria, of which Oyo State is part, has the highest concentration of pigs in the country with about $25 \%$ of the pig population in Nigeria (Majiyagbe and Lamorde, 1997). The objective of the present study is to assess helminth parasites of pigs in Ibadan, Oyo State, Nigeria.

\section{Materials and method Location of study}

The study was conducted at various locations around Ibadan metropolis where pigs are found in Oyo State, Nigeria and the laboratory work was done in the Laboratory of the Department of Veterinary Medicine, University of Ibadan. Ibadan covers an area of 70 square Kilometres and lies on the longitude $7.23^{\circ} \mathrm{N}, 3.5^{\circ} \mathrm{E}$.

\section{Sample collection}

About five grammes of fresh faecal samples were collected from the rectum of each of the pigs into labelled universal glass bottles and filled to the brim to exclude air as much as possible. Faecal samples were placed in ice-packed containers for transportation and later placed in a refrigerator at $4{ }^{\circ} \mathrm{C}$. The sex of various pigs, breed and appropriate weight were taken before the samples were collected. In all, a total of 154 pigs were sampled and laboratory examinations were carried out within 24 hours of sampling.

\section{Laboratory examinations}

The faecal samples were examined for helminth eggs in the laboratory within few hours of collection as previously described using the floatation technique and various helminth egg count were carried out for all the faecal samples using a McMaster slide as previously described by Soulsby (1982).

\section{Results}

The distribution of helminth eggs of pigs in both sexes is presented in Table 1. Of the total number of 154 faecal samples examined, $56(36.36 \%)$ were positive for helminth parasites out of which 38 $(24.67 \%)$ were males and $18(11.69 \%)$ were females. The eggs of helminth parasites found in this study were those of Ascaris spp. (12.34\%), Metastrongylus spp. (9.74\%), Oesophagostomum spp. (6.49\%), Paragonimus spp. (1.3\%), Hyostrongylus spp. (1.3\%) and Trichuris spp. (5.19\%) as seen in Plates 1, 2, 3, 4 and 5. Ascaris spp. (12.34\%) and Metastrongylus spp. (9.74\%) are the commonest parasites of pigs in the study.

The breed distribution of the pigs examined in the study is presented in Table 2. Of the $56(36.36 \%)$ positive samples for helminth parasites, $42(27.27 \%)$ were from large white breed, $10(6.49 \%)$ were crosses while $4(2.60 \%)$ were of indigenous breed. Eggs of helminth parasites were found highest in the large white breed of which Metastrongylus spp., Ascaris spp., Oesophagostomum spp. and Trichuris spp. accounting for 15 (9.74\%), 19(12.34\%) $10(6.49 \%)$ and $8(5.19)$ respectively as seen in Plates 1 to 5.

The mean eggs per gramme of faeces of various helminth parasite eggs in pigs examined is presented in Table 3. Trichuris spp. had the highest $500(29.07 \%)$ mean eggs per gramme of faeces, followed by Metastrongylus spp. with 480 mean epg (27.91\%) and Ascaris spp. with 294.7 mean epg $(17.14 \%)$. Others are Oesophagostomum spp. with 195 mean epg (11.34\%), Hyostrongylus spp. with 150 mean epg (8.72\%) and Paragonimus spp. with 100 mean epg (5.81\%) 
Adenaike

Table 1: Distribution of helminth eggs of pigs in both sexes in Ibadan

\begin{tabular}{|c|c|c|c|}
\hline \multirow[b]{2}{*}{ Helminth eggs } & \multicolumn{2}{|r|}{ Sex } & \multirow[b]{2}{*}{ Total } \\
\hline & Male & Female & \\
\hline Trichuris spp. (\%) & $5(3.25)$ & $3(1.95)$ & $8(5.19)$ \\
\hline Ascaris spp. (\%) & $13(8.44)$ & $6(3.90)$ & $19(12.34)$ \\
\hline Metastrongylus spp. (\%) & $14(9.09)$ & $1(0.65)$ & $15(9.74)$ \\
\hline Hyostrongylus spp. (\%) & $1(0.65)$ & $1(0.65)$ & $2(1.30)$ \\
\hline Paragonimus spp. (\%) & $1(0.65)$ & $1(0.65)$ & $2(1.30)$ \\
\hline Oesophagostomum spp. (\%) & $4(2.60)$ & $6(3.90)$ & $10(6.49)$ \\
\hline Total & $38(24.68)$ & $18(11.69)$ & $56(36.36)$ \\
\hline
\end{tabular}

Table 2: Breed distribution of pigs slaughtered in Ibadan

\begin{tabular}{lllll}
\hline & \multicolumn{3}{c}{ Breed } & \\
\cline { 2 - 4 } Helminth eggs & Large White & Indigenous & Cross & Total \\
\hline Trichuris spp. (\%) & $7(4.55)$ & $0(0.00)$ & $1(0.65)$ & $8(5.19)$ \\
Ascaris spp. (\%) & $13(8.44)$ & $1(0.65)$ & $5(3.25)$ & $19(12.34)$ \\
Metastrongylus spp. (\%) & $13(8.44)$ & $0(0.00)$ & $2(1.30)$ & $15(9.74)$ \\
Hyostrongylus spp. (\%) & $1(0.65)$ & $1(0.65)$ & $0(0.00)$ & $2(1.30)$ \\
Paragonimus spp. (\%) & $0(0.00)$ & $1(0.65)$ & $1(0.65)$ & $2(1.30)$ \\
Oesophagostomum spp. (\%) & $8(5.19)$ & $1(0.65)$ & $1(0.65)$ & $10(6.49)$ \\
Total & $42(27.27)$ & $4(2.60)$ & $10(6.49)$ & $56(36.36)$ \\
\hline Values in parenthesis are percentages & & & &
\end{tabular}

Values in parenthesis are percentages

Table 3: Mean eggs per gramme of faeces of helminths in pigs slaughtered in Ibadan

\begin{tabular}{ll}
\hline Helminth parasite & mean epg (\%) \\
\hline Trichuris spp. (\%) & $500(29.07)$ \\
Ascaris spp. (\%) & $294.7(17.14)$ \\
Metastrongylus spp. (\%) & $480(27.91)$ \\
Hyostrongylus spp. (\%) & $150(8.72)$ \\
Paragonimus spp. (\%) & $100(5.81)$ \\
Oesophagostomum spp. (\%) & $195(11.34)$ \\
Total & $\mathbf{1 7 1 9 . 7 ( 1 0 0 . 0 0 )}$ \\
\hline Valo
\end{tabular}

Values in parenthesis are percentages

\section{Discussion}

An assessment of helminth parasites of pigs in Ibadan was conducted and the prevalence of gastro-intestinal nematodes observed to be $36.36 \%$ in this study is comparable with previous reports from different parts of the country. Helminth parasites were found were those of Ascaris spp. (12.34\%), Metastrongylus spp. (9.74\%), Oesophagostomum spp. (6.49\%), Trichuris spp. (5.19\%), Paragonimus spp. (1.3\%) and Hyostrongylus spp. (1.3\%) with Ascaris spp. and Metastrongylus spp. being the commonest parasites of pigs. In a survey on the prevalence of swine diseases in Ijebu division of Ogun State, Talabi et al. (2010) found the following gastrointestinal nematode eggs: Ascaris sp. (45.26\%), Strongyles (10.22\%), Strongyloides sp. (5.11\%) and Trichuris sp. $(2.92 \%)$ in the faecal samples evaluated. In another study carried out in Plateau State however, Ascaris eggs were encountered in $90.40 \%$ of the faecal samples examined (Ajayi and Arabs, 1988). These nematodes are able to complete their life cycles in-doors under the intensive system of management, hence many surveys have shown that prevalence levels of infection to these helminths are closely related to hygiene and housing systems (Roepstorff and Nansen, 1994). In another investigation in Plateau State. Pam et al. (2013) examined 171 pigs for gastrointestinal parasites of which $35.09 \%$ 
Assessment of helminth parasites of pigs in Ibadan, Nigeria

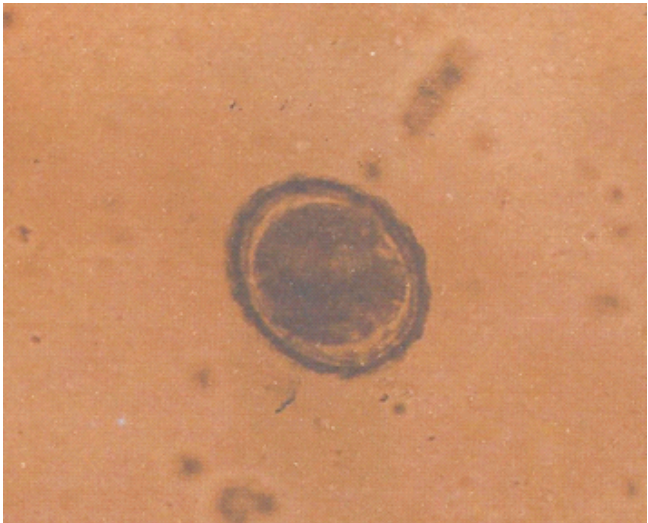

Plate 1: The egg of Ascaris spp. Mg. X 800

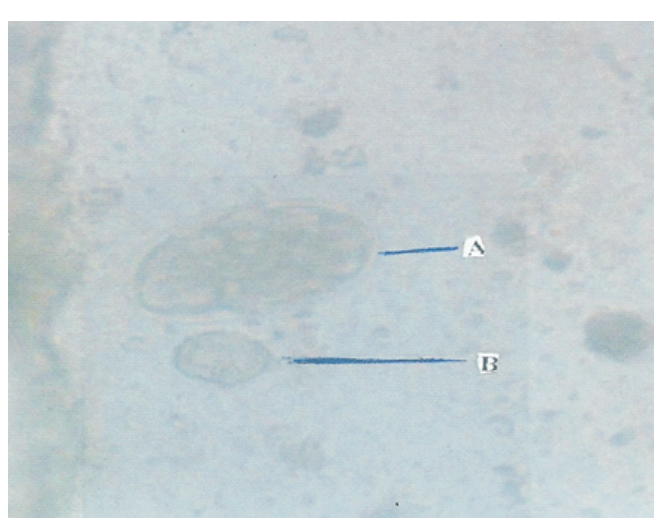

Plate 3: The eggs of (A) Oesophagostomum spp. and (B) Globocephallus spp. Mg. X 800

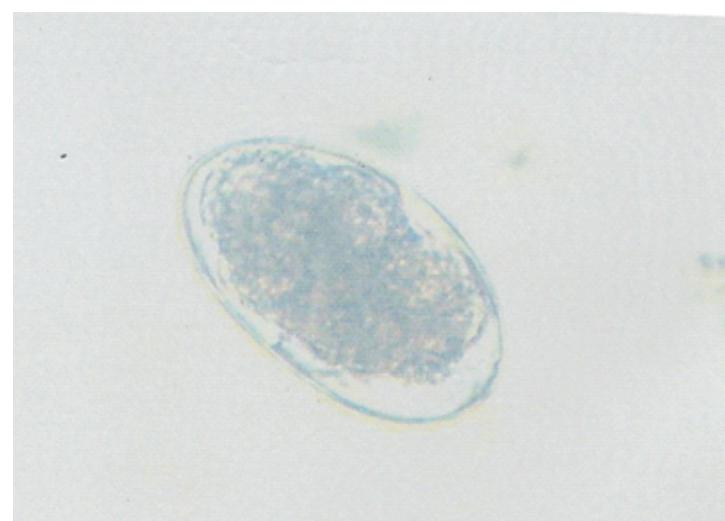

Plate 2: The egg of Metastrongylus spp. Mg. X 800

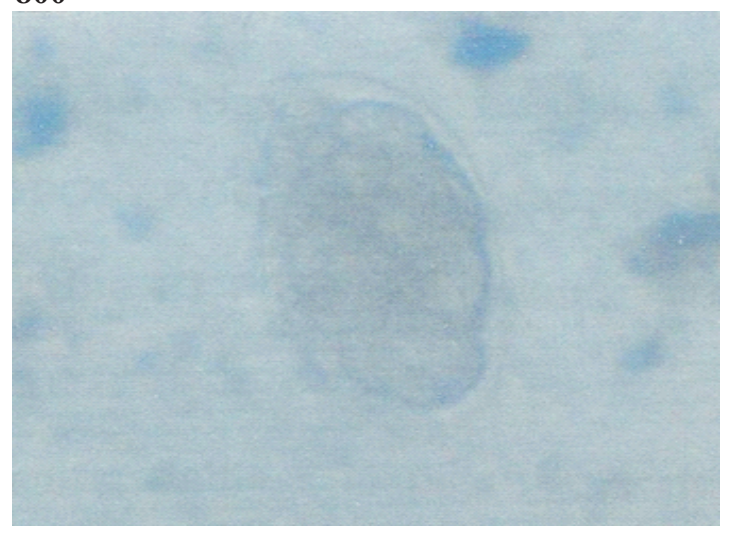

Plate 4: The egg of Hyostrongylus spp. Mg. X 800

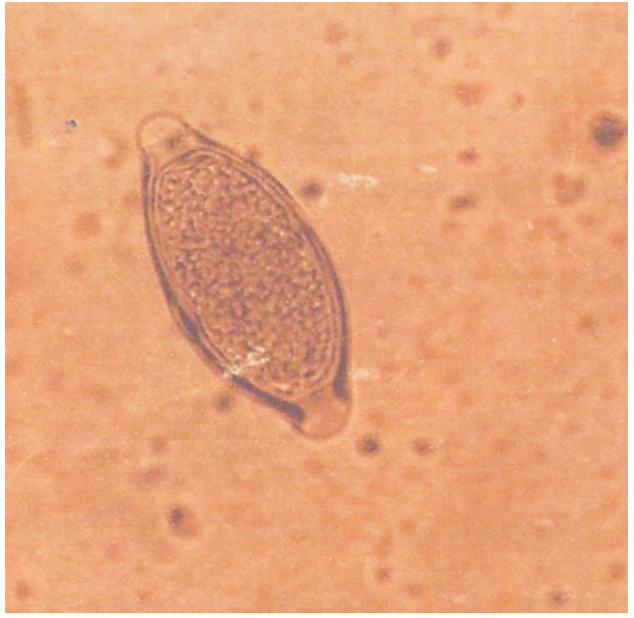

Plate 5: The egg of Trichuris spp. Mg. X 800 


\section{Adenaike}

pigs were positive and parasites found include Oesophagostomum dentatum, Hyostrongylus rubidus, Ascaris suum, Paragonimus westermanni, Metastrongylus spp. and Necator spp. The high incidence of helminth parasites in the tropics may be as a result of the favourable environmental conditions that promote the survival and proliferation of the helminths and these helminths are able to complete their life cycles in-doors under the intensive system of management (Talabi et al., 2010). Ascaris spp. is the commonest nematode of pigs found in this study as it accounted for a prevalence of $12.24 \%$. Ascarosis in pigs is caused by $A$. suum and heavy infections of the intestine with adult ascarid nematodes can cause digestive disturbances, poor growth in young animals, afebrile diarrhoea, intestinal obstruction and lowered resistance to other diseases. Migration of the immature stages through the lungs may results in coughing and dyspnoea (Talabi et al., 2004). Trichuris spp. had the highest mean eggs per gramme of faeces in this study. Trichuris suis is a swine whipworm, with a characteristic "whip-like" appearance is primarily a parasite of swine. Infections with T. Suis can cause diarrhoea, anorexia, anaemia, poor growth, dehydration and emaciation, but severity is usually related to the infective dose or concurrent bacterial enteritis. Both the larval and adult whipworms are normally found only in the intestines and they do not undergo tissue migration. Intestinal trichurosis is diagnosed by detecting characteristic Trichuris eggs in the faeces (Pittman et al., 2010). Whipworms can be isolated on many swine farms and often impose significant economic impacts by impeding weight gains and feed efficiency. A common signal of possible whipworm infection includes several poor-performing animals within a group of pigs that appear to be growing normally. However, heavy infections can cause haemorrhagic diarrhoea and emaciation, and may be confused clinically with swine dysentery or proliferative enteritis. Karanja et al. (2003) investigated the pathogenic effects associated with natural gastrointestinal helminth infections in pigs in Kenya. Partial obstruction of the small intestines whereby 35 and 40 adult worms were entwined into ropes was encountered in Ascaris suum infection. A mild reaction comprising hyperaemia and increased mucus production was also encountered in pigs infected by Trichostrongylus columbriformis. In the large intestines, mild lesions comprising circulatory disturbances namely petechial haemorrhages and/or mucosal congestion were encountered in pigs infected by Trichuris suis. In these pigs, the intestinal contents were loose and pasty. Those with mixed T. suis and Oesophagostomum spp. infection showed congestion as the main gross lesion and grossly visible nodules on the mucosa of the caecum and colon. The nodules measured a few millimetres to 10 $\mathrm{mm}$ in diameter and their centres looked like "volcano craters" whose floors were covered by creamy material.

\section{Conclusion}

The study showed that regular assessment of helminth parasites in the faeces of pigs in recommended for strategic treatment against helminth parasites and pig farmers are encouraged to prevent the environment from becoming contaminated by infective helminth larvae by practicing good standards of hygiene.

\section{References}

Ajayi, J. A. and Arabs, W. L. 1988. Helminths and Protozoa of Pigs on the Jos Plateau, Nigeria: Occurrence, Age incidence and Seasonal distribution. Bulletin of Animal Health and Production in 


\section{Assessment of helminth parasites of pigs in Ibadan, Nigeria}

Africa 36: 47-54.

Karanja, D. N., Ngatia, T. A., Wabacha, J. K., Bebora, L. C. and Ng'ang'a, C. J. 2011. Pathogenic effects associated with natural gastrointestinal helminth infections in pigs in Kenya. Bulletin of Animal Health and Production in Africa 59 (No 1): 53 59.

Majiyagbe, K. A. and Lamorde, A. G. 1997. Nationally Coordinated Research Programme on Livestock Diseases: Subsectoral goals, Performance and Medium-term research plans. Tropical Veterinarian 15: 75-83.

Pam, V. A., Daniel, L. N., Bata, S. I., Udokaninyene, A. D., Hassan, A. A., Kemza, S. Y., Igeh, C. P. and Ogbu, K. I. 2013. An Investigation of Haemo and Gastrointestinal Parasites of Pigs in Some Parts of Langtang North Local Government Area of Plateau State. Journal of Veterinary Advances 3: 79-86.

Pittman, J. S., Shepherd, G., Thacker, B. J. and Myers, G. H. 2010. Trichuris suis in finishing pigs: Case report and review. Journal of Swine Health and Production 18(6): 306-313.
Roepstorff, A. and Nansen, P. 1994. Epidemiology and control of helminth infections in pigs under intensive and non-intensive production systems. Veterinary Parasitology 54: 69-85.

Soulsby, E. J. L. 1982. Helminthes, Arthropods and Protozoa of Domesticated Animals. $7^{\text {th }}$ edition, London, U.K.; Bailere Tindall, 809 pp.

Talabi, A. O., Oyekunle, M. A. and Soremekun, A. N. 2003. A comparative study of the efficacies of two brands of Ivermectin on gastro-intestinal nematodes of cattle. Nigerian Veterinary Journal 24 (No 3):26-29.

Talabi, A. O., Oyekunle, M. A., Onasanya, A. S., Tijani, L. A., Sosanya, O. S. and Ettu, R. O. 2004. Comparison of the efficacies of Diazinon + Albendazole, Ivomec and Ivojec on the control of gastrointestinal nematodes and ectoparasites of pigs. African Journal of Livestock Extension 3: 55-58.

Talabi, A. O., Oyekunle, M. A., Abiola, J. O., Makinde, G. E. O., Akinleye, S. O., Ettu, R. O. and Oyejobi, Y. A. 2010. Prevalence of swine diseases in Ijebu division of Ogun State. Nigerian Journal of Animal Production 38: (No 1) 125-129.

Received: $20^{\text {th }}$ November, 2019 Accepted: $2^{\text {nd }}$ March, 2020 